OPEN ACCESS

Edited by:

Carlo Alviggi,

University of Naples

Federico II, Italy

Reviewed by:

Roberta Venturella,

Università degli studi Magna

Graecia di Catanzaro, Italy

Alessandro Conforti,

University of Naples Federico II, Italy

${ }^{*}$ Correspondence:

Pavitra Dewda

pavitra.dewda@merckgroup.com

Specialty section:

This article was submitted to

Reproduction,

a section of the journal

Frontiers in Endocrinology

Received: 17 January 2018 Accepted: 10 April 2018

Published: 26 April 2018

Citation:

Esteves SC, Khastgir G, Shah J,

Murdia K, Gupta SM, Rao DG,

Dash S, Ingale K, Patil M, Moideen K,

Thakor $P$ and Dewda P (2018)

Association Between Progesterone

Elevation on the Day of Human

Chronic Gonadotropin Trigger and Pregnancy Outcomes After

Fresh Embryo Transfer in In Vitro

Fertilization/Intracytoplasmic

Sperm Injection Cycles.

Front. Endocrinol. 9:201.

doi: 10.3389/fendo.2018.00201

\section{Association Between Progesterone Elevation on the Day of Human Chronic Gonadotropin Trigger and Pregnancy Outcomes After Fresh Embryo Transfer in In Vitro Fertilization/Intracytoplasmic Sperm Injection Cycles}

\author{
Sandro C. Esteves ${ }^{1,2,3}$, Gautam Khastgir ${ }^{4}$, Jatin Shah ${ }^{5}$, Kshitiz Murdia, \\ Shweta Mittal Gupta ${ }^{7}$, Durga G. Rao ${ }^{8}$, Soumyaroop Dash ${ }^{9}$, Kundan Ingale ${ }^{10}$,
} Milind Patil ${ }^{11}$, Kunji Moideen ${ }^{12}$, Priti Thakor ${ }^{13}$ and Pavitra Dewda ${ }^{13 *}$

\begin{abstract}
${ }^{1}$ ANDROFERT, Andrology and Human Reproduction Clinic, Campinas, Brazil, ${ }^{2}$ Division of Urology, Department of Surgery, Faculty of Medical Sciences, University of Campinas (UNICAMP), Campinas, Brazil, ${ }^{3}$ Faculty of Health, Aarhus University, Aarhus, Denmark, ${ }^{4}$ BIRTH, Kolkata, India, ${ }^{5}$ Mumbai Fertility Center - Kamala Polyclinic \& Nursing Home, Mumbai, India, ${ }^{6}$ Indira IVF Group, Udaipur, India, ${ }^{7}$ Sir Ganga Ram Kolmet Hospital, New Delhi, India, ${ }^{8}$ Oasis Centre for Reproductive Medicine, Hyderabad, India, ${ }^{9}$ Srishti Assisted Fertility \& Advanced Laparoscopy Center, Srishti Hospital, Moolakulam, India, ${ }^{10}$ Nirmiti Clinic, Centre for Assisted Reproduction, Chinchwad, India, ${ }^{11}$ Shobha Nursing Home, Solapur, India, ${ }^{12}$ ARMC IVF Fertility Centre, Kozhikode, India, ${ }^{13}$ Merck Limited, Mumbai, India
\end{abstract}

Progesterone elevation (PE) during the late follicular phase of controlled ovarian stimulation in fresh embryo transfer in vitro fertilization (IVF)/intracytoplasmic sperm injection cycles has been claimed to be associated with decreased pregnancy rates. However, the evidence is not unequivocal, and clinicians still have questions about the clinical validity of measuring $P$ levels during the follicular phase of stimulated cycles. We reviewed the existing literature aimed at answering four relevant clinical questions, namely (i) Is gonadotropin type associated with PE during the follicular phase of stimulated cycles? (ii) Is PE on the day of human chorionic gonadotropin (hCG) associated with negative fresh embryo transfer IVF/intracytoplasmic sperm injection (ICSI) cycles outcomes in all patient subgroups? (iii) Which $P$ thresholds are best to identify patients at risk of implantation failure due to PE in a fresh embryo transfer? and (iv) Should a freeze all policy be adopted in all the cycles with PE on the day of hCG? The existing evidence indicates that late follicular phase progesterone rise in gonadotropin releasing analog cycles is mainly caused by the supraphysiological stimulation of granulosa cells with exogenous follicle-stimulating hormone. Yet, the type of gonadotropin used for stimulation seems to play no significant role on progesterone levels at the end of stimulation. Furthermore, $\mathrm{PE}$ is not a universal phenomenon with evidence indicating that its detrimental consequences on pregnancy outcomes do not affect all patient populations equally. Patients with high ovarian response to control ovarian stimulation are more prone to exhibit PE at the late follicular phase. However, in studies showing an overall detrimental effect of 
PE on pregnancy rates, the adverse effect of PE on endometrial receptivity seems to be offset, at least in part, by the availability of good quality embryo for transfer in women with a high ovarian response. Given the limitations of the currently available assays to measure progesterone at low ranges, caution should be applied to adopt specific cutoff values above which the effect of progesterone rise could be considered detrimental and to recommend "freeze-all" based solely on pre-defined cutoff points.

Keywords: assisted reproductive technology, controlled ovarian stimulation, human chorionic gonadotropin trigger, intracytoplasmic sperm injection, in vitro fertilization, late follicular phase, pregnancy outcomes, progesterone elevation

\section{INTRODUCTION}

Progesterone $(\mathrm{P})$ is essential before and during pregnancy as it plays a critical role in supporting the endometrium and hence survival of the conceptus (1). In the natural cycle, preovulatory $\mathrm{P}$ secretion facilitates the action of estrogen on the pituitary; the latter is the key factor to induce the mid-cycle luteinizing hormone $(\mathrm{LH})$ peak. Progesterone also stimulates the mid-cycle follicle-stimulating hormone (FSH) surge, which is important to support the expression of $\mathrm{LH}$ receptors in the granulosa layer $(2,3)$. Notably, most circulating $\mathrm{P}(\sim 95 \%)$ is produced in the intrafollicular compartment by the granulosa cells (GCs) via the action of $3 \beta$-HSD that catalyzes the conversion of pregnenolone (delta-4 pathway) under LH influence $(4,5)$. After ovulation, the corpus luteum is formed and $\mathrm{P}$ is produced in both luteinized theca and GCs under the effect of endogenous LH activity (6). In early pregnancy, human chorionic gonadotropin (hCG) secreted by syncytio trophoblast cells rescues the corpus luteum and maintains luteal function until placental steroidogenesis is established (7). As such, progesterone elevation (PE) and its sustained levels have been considered essential to elicit the endocrine signals responsible for initiating the period of endometrial receptivity to embryo implantation $(8,9)$.

Late follicular phase PE, commonly defined as P levels of $1.5 \mathrm{ng} / \mathrm{ml}(4.77 \mathrm{nmol} / \mathrm{l})$ or greater at the day of hCG trigger, has been reported in 6-30\% of controlled ovarian stimulation (COS) cycles (10-14). The observation of worse pregnancy outcomes in fresh embryo transfer in vitro fertilization (IVF)/ intracytoplasmic sperm injection (ICSI) cycles among patients with $\mathrm{PE}$ compared to non-PE has prompted clinicians to monitor progesterone levels during the late follicular phase or at the day of hCG trigger. A policy of freezing all embryos from a fresh IVF/ ICSI cycle and replacing the embryos in a subsequent cycle has been advocated as a solution to avoid the potential negative effect of PE on pregnancy $(15,16)$.

In non-gonadotropin releasing hormone $(\mathrm{GnRH})$ analog cycles, premature PE can be explained by an early preovulatory LH elevation $(17,18)$, which results in endometrial asynchrony that ultimately affects implantation and pregnancy (19). In contrast, follicular phase $\mathrm{PE}$ cannot be attributed to premature $\mathrm{LH}$ surge in GnRH analog cycles, since the pituitary is suppressed (20-24). Furthermore, whereas some investigators have reported an inverse association between pregnancy rates in fresh embryo transfer IVF/ICSI cycles and PE, the evidence is not unequivocal thus making the universal application of the freeze-all policy debatable (11).
Currently, many clinicians have questions about the clinical validity of measuring P levels during the follicular phase of stimulated cycles. Among several concerns, it is not clear which patients might benefit from $\mathrm{P}$ monitoring and what would be the practical implications of PE to pregnancy success in an IVF/ICSI program. In this review, we summarize the recent evidence concerning the clinical implications of PE on Assisted Reproductive Technology (ART) cycles outcomes and identify gaps of knowledge as well as opportunities for future research.

\section{REVIEW CRITERIA}

\section{Search Criteria}

An extensive search of studies published in the past 10 years by examining the relationship between $\mathrm{P}$ levels on the day of hCG trigger and pregnancy outcomes in fresh embryo transfer IVF/ICSI cycles was performed using PubMed and MEDLINE. The start and end dates for the searches were January 2006 and February 2017, respectively.

\section{Eligibility Criteria}

Specifically, our study was designed to answer clinical questions raised by the group of authors with clinical experience in IVF/ ICSI (SE, GK, JS, KM, SG, DR, SD, KI, and MP), namely (i) Is gonadotropin type associated with $\mathrm{PE}$ during the follicular phase of stimulated cycles? (ii) Is PE on the day of hCG associated with negative fresh embryo transfer IVF/ICSI outcomes in all patient subgroups? (iii) Which $\mathrm{P}$ thresholds are best to identify patients at risk of implantation failure due to $\mathrm{PE}$ in a fresh embryo transfer? and (iv) Should a freeze all policy be adopted in all the cycles with PE on the day of hCG? Therefore, eligible studies were those that provided evidence to answer one or more questions above.

\section{Study Selection}

The overall strategy for study identification and data extraction was based on the following key words: "assisted reproductive technology," "controlled ovarian stimulation," "intracytoplasmic sperm injection," "in vitro fertilization," "progesterone levels," "hCG trigger," "pregnancy outcomes," with the filters "humans," and "English language." Data only published in conference or meeting proceedings, websites, or books were not included. Articles were only included if hCG trigger alone followed by conventional luteal phase support, which specifically means luteal supplementation with progesterone administration, and fresh embryo transfers were carried out. Oocyte donation and frozen-thawed embryo 
transfer cycles were excluded. Case reports and letters were not considered. Articles published before the start search date and book-chapter citations provided conceptual content only.

\section{RESULTS AND DISCUSSION}

The search retrieved a total of 31 articles that specifically addressed at least one of the formulated clinical questions. The Table S1 in Supplementary Material lists the eligible studies included to address the key questions.

\section{Is Gonadotropin Type Associated With PE During the Follicular Phase of Stimulated Cycles?}

The menotropin versus recombinant FSH IVF trial (MERIT) compared to ongoing pregnancy rates (OPR) in 731 young, normogonadotrophic women undergoing IVF after stimulation with highly purified human menopausal gonadotrophin (HP-hMG; $n=363$ ) or recombinant FSH (rFSH; $n=368$ ) (25). The threshold value for defining serum $P E$ in this study was $4 \mathrm{nmol} / \mathrm{l}(1.25 \mathrm{ng} / \mathrm{ml})$, measured on the last day of stimulation. The serum P levels were higher in rFSH-treated patients than in HP-hMG-treated patients, with the former showing a higher incidence of $\mathrm{PE}(23 \%$, $3.4 \mathrm{nmol} / \mathrm{l}$ versus $11 \%, 2.6 \mathrm{nmol} / \mathrm{l}$; $p<0.001)$. In the study mentioned above, patients showing higher $\mathrm{P}$ values had lower fresh embryo implantation rate (HP-hMG group: 24 versus 19\%, not statistically significant; rFSH group: 23 versus $11 \%, p=0.025$ ). The authors concluded that late follicular phase PE affected fresh embryo transfer IVF/ICSI outcomes, with PE being more common with the use of rFSH than HP-hMG, however, it is important to note that values of $\mathrm{PE}$ are below $4.77 \mathrm{nmol} / \mathrm{l}(1.5 \mathrm{ng} / \mathrm{l})$ in both groups implying statistically significant values could be clinically irrelevant (25).

Contrary results were reported by Andersen et al. who performed a post hoc analysis of data from a randomized controlled trial (RCT) that included 475 women younger than 40 years subjected to IVF/ICSI (26). The primary aim of the study was to investigate whether the addition of recombinant $\mathrm{LH}(\mathrm{rLH})$ or FSH from day 6 of stimulation onward impacted pregnancy rates in $\mathrm{GnRH}$ agonist cycles. Moreover, the authors evaluated whether the addition of rLH in the second half of the follicular phase influenced serum P levels measured on the day of hCG trigger. P levels were determined on day 1, i.e., before exogenous FSH administration, and on the day of hCG trigger. Although patients receiving rLH had higher LH levels at the end of stimulation than those receiving $\mathrm{rFSH}$ alone, there were no differences in pregnancy rates and late follicular phase $\mathrm{P}$ levels between groups. In this study, $\mathrm{P}$ levels were associated with both the number of developing follicles and retrieved oocytes and partly to the late follicular phase LH concentration. Interestingly, higher pregnancy rates were reported in women with $\mathrm{P}$ concentration $>7 \mathrm{nmol} / \mathrm{l}$ $(>2.20 \mathrm{ng} / \mathrm{ml})$ in the late follicular phase, which coincided with those developing high number of follicles (26).

In another study, Kolibianakis et al. (27) pooled data from five COS-IVF trials (28-32) using either GnRH antagonists or agonists that evaluated the impact of the type of gonadotropin,
rFSH alone, rFSH combined with rLH, HP-hMG alone, and rFSH combined with HP-hMG on PE. The authors found that $\mathrm{P}$ levels in the late follicular phase were associated with the number of oocytes retrieved and serum estradiol levels, irrespective of type of $\mathrm{GnRH}$ analog, but not with the type of gonadotropin administered. Furthermore, there was no association between PE and duration of stimulation or FSH requirement. Subsequently, Requena et al. corroborated these aforementioned findings by showing that the mean serum P levels did not differ significantly with respect to the type of gonadotropin used for COS: $\mathrm{rFSH}+\mathrm{rLH}(n=377, \mathrm{P}: 1.01 \mathrm{ng} / \mathrm{ml}), \mathrm{rFSH}$ alone $(n=728$, P: $1.06 \mathrm{ng} / \mathrm{ml}), \mathrm{rFSH}+\mathrm{HP}-\mathrm{hMG}(n=1,375 ; \mathrm{P}: 1.30 \mathrm{ng} / \mathrm{ml})$, and HP-hMG alone ( $n=370$; P: $1.10 \mathrm{ng} / \mathrm{ml}$ ) (33). Last, a randomized, open-label, assessor-blind study comparing the efficacy and safety of HP-hMG and rFSH for COS reported that at the end of stimulation, the mean $\mathrm{P}$ levels were was not significantly different between HP-hMG $(3.1 \pm 3.4 \mathrm{nmol} / \mathrm{l})$ and $\mathrm{rFSH}(3.1 \pm 3.3 \mathrm{nmol} / \mathrm{l})$ treatment groups (34). The characteristics and main findings of the studies mentioned above are summarized in Table $\mathbf{1 .}$

Collectively, these findings suggest that gonadotropin type does not play a major role to PE in COS. During follicular phase, the GCs are supraphysiologically stimulated by gonadotropins, which may result in increased serum $P$ levels (36). As the pituitary is normally suppressed by $\mathrm{GnRH}$ analogs during COS, the serum $P$ levels in stimulated cycles represent the total follicle output of GCs $(17,33)$. The findings that $\mathrm{LH}$ activity provided by rLH of hCG content in hMG preparations is unable to influence $P$ levels is explained by the fact that cytochrome 17a-hydroxylase-C17, 20 lyase (P450-17a), the key enzyme driving the conversion of intrafollicular $\mathrm{P}$ to estradiol, is virtually absent in the intrafollicular compartment (36-38), which makes the conversion of $\mathrm{P}$ to estradiol negligible in humans (39). PE is rather dependent on the overall GC output and is, therefore, associated with the number of follicles, oocytes, and E2 levels. Notwithstanding, some evidence suggests that the use of rFSH may be associated with higher $\mathrm{P}$ output than urinary gonadotropin normal and high responders, due to the higher potency of rFSH than urinary products $(35,40)$.

\section{Is PE on the Day of hCG Associated With Negative Fresh Embryo Transfer IVF-ICSI Outcomes in All Patient Subgroups?}

In a systematic review and meta-analysis including 63 studies and over 60,000 IVF/ICSI cycles, Venetis et al. reported that late follicular phase PE was detrimental to fresh embryo transfer pregnancy rates. PE affected pregnancy success with levels as low as $0.8-1.1 \mathrm{ng} / \mathrm{ml}$ (OR: $0.79,95 \% \mathrm{CI}: 0.67-0.95)$, which increased as the level reaches $1.2 \mathrm{ng} / \mathrm{ml}$ (OR: $0.67,95 \% \mathrm{CI}: 0.53-0.84$ ), and becomes stable thereafter (12). Along the same lines, Bosh et al. showed an association between P levels $>1.5 \mathrm{ng} / \mathrm{ml}$ at the day of hCG administration and fresh embryo transfer IVF/ICSI pregnancy outcomes. The authors examined their database of 4,032 patients subjected to IVF/ICSI and found that OPRs were higher in patients with serum P levels $\leq 1.5 \mathrm{ng} / \mathrm{ml}$ than those with P levels $>1.5 \mathrm{ng} / \mathrm{ml}$ (31.0 versus $19.1 \% ; P=0.00006)$ (10).

However, the evidence is not unequivocal as Miller et al. showed that the elevation of P level in 293 patients subjected to 
TABLE 1 | Characteristics of included studies to discuss if gonadotropin type is associated with progesterone elevation (PE) during the follicular phase of stimulated cycles.

\begin{tabular}{|c|c|c|c|c|}
\hline $\begin{array}{l}\text { Study and year } \\
\text { (reference) }\end{array}$ & Patient characteristics & Ovarian stimulation regimen & Progesterone threshold & PE incidence \\
\hline $\begin{array}{l}\text { Menotrophin } \\
\text { versus } \\
\text { recombinant FSH } \\
\text { (rFSH) } N F \text { trial } \\
\text { (MERIT) (25) }\end{array}$ & $\begin{array}{l}\text { Study included a total of } 731 \\
\text { young, normogonadotropic } \\
\text { women undergoing IVF, patients } \\
\text { were divided in two groups }\end{array}$ & $\begin{array}{l}\text { Stimulation was performed with highly } \\
\text { purified human menopausal gonadotropin } \\
\text { (HP-hMG; } n=363 \text { ) or rFSH ( } n=368) \text {. } \\
\text { P concentration was measured on the } \\
\text { last day of stimulation }\end{array}$ & $\begin{array}{l}\text { The threshold value for } \\
\text { defining serum PE was } \\
4 \mathrm{nmol} / \mathrm{l}(1.25 \mathrm{ng} / \mathrm{ml})\end{array}$ & $\begin{array}{l}\text { The serum } \mathrm{P} \text { levels were higher in } \\
\text { rFSH-treated patients than in the } \\
\text { HP-HMG-treated patients, with the } \\
\text { former showing a higher incidence } \\
\text { of PE ( } 23 \text { versus } 11 \% ; p<0.001 \text { ) }\end{array}$ \\
\hline $\begin{array}{l}\text { Andersen CY } \\
\text { et al. (26) }\end{array}$ & $\begin{array}{l}\text { Study included a total of } 475 \\
\text { women age with } 40 \text { years, } \\
\text { undergoing IVF or ICSI with a } \\
\text { regular ( } 21-35 \text { days) menstrual } \\
\text { cycle and basal serum FSH } \\
\text { concentration of }<10 \text { IU/I on } \\
\text { menstrual cycle day } 2-5\end{array}$ & $\begin{array}{l}\text { Stimulation was performed with } \mathrm{GnRH} \\
\text { agonist and } \mathrm{FSH} \text { in one group }(n=247) \text {, } \\
\text { in another group }(n=228 \text { ) patients were } \\
\text { administered } \mathrm{GnRH} \text { agonist, rFSH with } \\
\text { rLH from day } 6 \text { of stimulation. } \\
\mathrm{P} \text { concentration was measured on day } 1 \text {, } \\
\text { prior to exogenous FSH administration, } \\
\text { and on the day of hCG administration }\end{array}$ & $\begin{array}{l}\text { The threshold value for } \\
\text { defining serum PE was } \\
4.77 \mathrm{nmol} / \mathrm{l}(1.5 \mathrm{ng} / \mathrm{ml})\end{array}$ & $\begin{array}{l}\text { The average progesterone } \\
\text { concentration on the day of ovulation } \\
\text { induction (day of HCG administration) } \\
\text { did not differ between those who } \\
\text { received embryo transfer and } \\
\text { those who did not [mean } \pm S D \text {, } \\
4.38 \pm 3.90 \mathrm{nmol} / /,(n=419), \\
\text { versus } 3.99 \pm 2.16 \mathrm{nmol} / \mathrm{l},(n=56) \text {, } \\
\text { respectively] }\end{array}$ \\
\hline Requena et al. (33) & $\begin{array}{l}\text { A total of } 2,850 \text { infertile women } \\
\text { who were classified as high } \\
\text { responders (high response was } \\
\text { defined as women who had } \\
\geq 20 \text { oocytes retrieved or whose } \\
\text { estradiol levels were } \geq 3,000 \mathrm{pg} / \mathrm{ml} \text { ) } \\
\text { and were undergoing assisted } \\
\text { reproduction techniques for the } \\
\text { last } 2 \text { years were included in this } \\
\text { retrospective study }\end{array}$ & $\begin{array}{l}\text { Ovarian stimulation was performed by one } \\
\text { of four possible methods: recombinant } \\
\text { follicle stimulating hormone (rFSH) } \\
\text { alone; rFSH combined with recombinant } \\
\text { luteinizing hormone (rLH); highly purified } \\
\text { human-menopausal gonadotropin } \\
\text { (HP-hMG) alone; or rFSH combined with } \\
\text { HP-hMG }\end{array}$ & $\begin{array}{l}\text { The threshold value for } \\
\text { defining serum PE was } \\
\text { following in different } \\
\text { groups: }<0.5 \mathrm{ng} / \mathrm{ml}(<\mathrm{p} 10) \text {, } \\
0.50-0.70 \mathrm{ng} / \mathrm{ml}(\mathrm{p} 10-\mathrm{p} 25) \text {, } \\
0.71-1.00 \mathrm{ng} / \mathrm{ml} \text { (p25-p50), } \\
1.01-1.40 \mathrm{ng} / \mathrm{ml} \text { (p50-p75), } \\
1.41-1.80 \mathrm{ng} / \mathrm{ml}(\mathrm{p} 75-\mathrm{p} 90) \text {, } \\
\text { and }>1.81 \mathrm{ng} / \mathrm{ml}(>p 90)\end{array}$ & $\begin{array}{l}\text { No significant differences in the } \\
\text { mean progesterone concentration } \\
\text { with respect to the type of } \\
\text { gonadotropin that was used for } \\
\text { ovarian stimulation: } \mathrm{rFSH} \text { alone } \\
(n=728 \text {, progesterone } 1.06 \mathrm{ng} / \mathrm{ml}) \text {, } \\
\text { rFSH + rLH ( } n=377 \text {, progesterone } \\
1.01 \mathrm{ng} / \mathrm{ml}), \mathrm{HP}-\mathrm{hMG} \text { alone } \\
(n=370 ; \text { progesterone } 1.10 \mathrm{ng} / \mathrm{ml}) \text {, } \\
\text { and rFSH + HP-hMG }(n=1,375 ; \\
\text { progesterone } 1.30 \mathrm{ng} / \mathrm{ml})\end{array}$ \\
\hline Devroey et al. (34) & $\begin{array}{l}\text { Study included women aged } \\
21-34 \text { years with a body mass } \\
\text { index (BMI) of } 18-25 \mathrm{~kg} / \mathrm{m}^{2} ; \\
\text { primarydiagnosis of infertility } \\
\text { being unexplained infertility or } \\
\text { mild male factor; eligible for ICSI, } \\
\text { infertile for } 12 \text { months before } \\
\text { randomization; with regular } \\
\text { menstrual cycles of } 24-35 \text { days }\end{array}$ & $\begin{array}{l}\text { Controlled ovarian stimulation was } \\
\text { performed with HP-hMG or rFSH in a } \\
\text { GnRH antagonist cycle with compulsory } \\
\text { single-blastocyst transfer on day } 5 \text { in one } \\
\text { fresh or subsequent frozen blastocyst } \\
\text { replacement in natural cycles }\end{array}$ & $\begin{array}{l}\text { The threshold value for } \\
\text { defining serum PE was } \\
3.18 \mathrm{nmol} / \mathrm{l}(1.0 \mathrm{ng} / \mathrm{ml})\end{array}$ & $\begin{array}{l}\text { The average serum P level and the } \\
\text { proportion of patients with serum } \\
\mathrm{P} \text { concentrations above } 4 \mathrm{nmol} / \mathrm{l} \\
\text { at the end of stimulation ( } 16 \% \text { in } \\
\text { the HP-hMG group and } 14 \% \text { in the } \\
\text { rFSH group) were similar between } \\
\text { the treatment groups }\end{array}$ \\
\hline Lawrenz et al. (35) & $\begin{array}{l}\text { ENGAGE study: a total of 1,506 } \\
\text { women aged 18-36 years } \\
\text { undergoing IVF stimulation cycles } \\
\text { PURSUE study: a total of 1,390 } \\
\text { women aged } 35-42 \text { years } \\
\text { undergoing IVF stimulation cycles } \\
\text { In both studies, women had a } \\
\text { body weight of between } 50 \text { and } \\
90 \mathrm{~kg} \text {, regular menstrual cycles }\end{array}$ & $\begin{array}{l}\text { For ENGAGE study: stimulation protocol } \\
\text { included either a single injection of } \\
150 \mathrm{mg} \text { CFA or daily injections of } 200 \mathrm{IU} \\
\text { rFSH in the first week of stimulation, using } \\
\text { a standard GnRH antagonist protocol } \\
\text { For PURSUE study: stimulation protocol } \\
\text { included either a single injection of } \\
150 \text { mg of CFA or daily } 300 \mathrm{IU} \text { of rFSH } \\
\text { for the first week, again using a standard } \\
\text { GnRH antagonist protocol. In both trials, } \\
\text { daily rFSH was continued until three } \\
\text { follicles reached }>17 \mathrm{~mm} \text { in size }\end{array}$ & $\begin{array}{l}\text { The threshold value for } \\
\text { defining serum PE was } \\
1.5 \mathrm{ng} / \mathrm{ml} \text {. PE was analyzed } \\
\text { on day } 8 \text { of stimulation }\end{array}$ & $\begin{array}{l}\text { Of patients with CFA, only } \\
\text { stimulation } 5.4 \% \text { ( } 13 / 239 \text { patients) } \\
\text { showed a PE above } 1.5 \mathrm{ng} / \mathrm{ml} \\
\text { on day of hCG trigger, whereas } \\
\text { patients with rFSH stimulation } \\
\text { had a significant higher incidence } \\
\text { of PE (18.3\%; } 62 / 339 \text { patients) } \\
\text { ( } p<0.001)\end{array}$ \\
\hline
\end{tabular}

COS with hMG and/or FSH in a GnRH agonist protocol did not affect oocyte quality and pregnancy rate (41). The findings of Miller et al. were corroborated by Hamdine et al. who conducted a prospective intervention study including 158 IVF-ICSI patients (42). The authors showed that the incidence of $\mathrm{PE}(>1.5 \mathrm{ng} / \mathrm{ml})$ was $13.3 \%$, but OPRs were not significantly different between patients with normal P levels and PE (27.0 versus 19.0\%). Furthermore, no differential impact of early or late GnRH antagonist initiation on the effect of elevated or normal P on OPR was observed. Likewise, the study of Andersen et al. mentioned above (26) reported that despite being strongly associated with the number of follicles and retrieved oocytes, late-follicular phase progesterone concentrations was not associated with clinical pregnancy rates (CPRs).

Recently, it has been suggested that the impact of PE on IVF/ ICSI may vary according to the affected population. In one study, Griesinger and colleagues analyzed the data from six IVF/ICSI clinical trials to investigate the impact of $\mathrm{P}$ measured on the day of hCG trigger on fresh embryo transfer pregnancy outcomes, using the cutoff point of $1.5 \mathrm{ng} / \mathrm{ml}$. Patients were stratified according to the number of oocytes retrieved after COS: low (1-5 oocytes), normal (6-18 oocytes), and high ( $>18$ oocytes). The incidence of PE was 4.5 and $19.0 \%$ in low responders and high responders, 
respectively. Overall, OPRs per started cycle were significantly lower in women with PE [odds ratio (25): 0.55; 95\% CI: 0.37-0.81]. However, a subgroup analysis showed that $\mathrm{P}$ level $>1.5 \mathrm{ng} / \mathrm{ml}$ was associated with decreased pregnancy rates in low to normal responders, but not in high responders (11). In their study, OPRs in high responders with PE were higher than normal responder counterparts. In women without P elevation, the observed OPR increased from $29.9 \%$ (1-5 oocytes) to $39.2 \%$ (>18 oocytes). By contrast, women with elevated P showed an increase in OPR from $18.2 \%$ (1-5 oocytes) to $43.2 \%$ (>18 oocytes). Compared with the subjects without $\mathrm{P}$ elevation, the observed OPR were numerically lower in all subsets for the women with elevated $\mathrm{P}$ except for the high responders ( $>18$ oocytes).

Similar results were reported by Requena et al. retrospectively analyzing the effect of $\mathrm{PE}$ on fresh embryo transfer IVF/ICSI pregnancy outcomes of 2,850 women classified as high responders (33). The high ovarian response was defined as having $\geq 20$ oocytes or estradiol $\geq 3,000 \mathrm{pg} / \mathrm{ml}$. The patients were subgrouped into six categories based on the level of serum $P$ on day of hCG, as $<0.5,0.50-0.70,0.71-1.00,1.01-1.40,1.41-1.80$, and $>1.81 \mathrm{ng} / \mathrm{ml}$. The authors observed that $\mathrm{P}$ levels neither had a negative impact on the oocyte quality and endometrial receptivity nor did it affect pregnancy success. Only in the group of P level $>1.80 \mathrm{ng} / \mathrm{ml}$ there was a marginally significant negative impact on pregnancy rates (OR: $0.73,95 \%$ CI: 0.61 to 0.99 ) (33). Last, a retrospective analysis of 1,800 IVF/ICSI cycles performed by Cruz et al., who stratified patients by high $(P>1.5 \mathrm{ng} / \mathrm{ml})$ or low $(P<1.5 \mathrm{ng} /$ $\mathrm{ml}$ ) concluded that $\mathrm{PE}$ in high ovarian responders did not impact fresh embryo transfer IVF/ICSI outcomes. The authors showed no significant differences in the analyzed parameters, namely, number of retrieved oocytes $(17.2 \pm 0.8$ versus $17.3 \pm 0.4)$, number of transferred embryos $(1.81 \pm 0.08$ versus $1.85 \pm 0.02)$, pregnancy rate (59.9 versus $54.6 \%)$, implantation rate $(41.2$ versus $39.7 \%$ ), and miscarriage rate (22.6 versus $28.6 \%$ ) for high and low progesterone levels respectively in case of high ovarian response (43).

It has been suggested that the likely reason for the negligible effect of PE on cycle outcome of high responders relates to the availability of high-quality embryos for transfer, including blastocysts, which could circumvent a possible adverse endometrial environment for implantation $(42,44)$. This hypothesis has been confirmed by the data of an early study by Papanikolaou et al., in which the impact of PE on pregnancy outcome was compared between day 3 and blastocyst single embryo transfers. The authors' analyzed data from 482 patients undergoing single ET after COS with GnRH antagonist associated with $\mathrm{rFSH}$. The incidence of PE (P above $1.5 \mathrm{ng} / \mathrm{ml}$ on the day of hCG administration) was $18.2 \%$. The authors reported that PE did not affect pregnancy outcome in fresh blastocyst transfer cycles. In contrast, even a modest rise in $\mathrm{P}$ affected the pregnancy outcome in patients with day 3 embryo transfers (29).

In conclusion, there is conflicting data on the impact of late follicular phase PE on fresh embryo transfer IVF/ICSI outcomes. Although PE has been associated with decreased pregnancy rates in several studies, PE does not seem to affect all patient populations equally with high responders with $\mathrm{PE}$ achieving similar pregnancy success than counterparts without PE. In studies showing an overall detrimental effect of PE on pregnancy rates, the adverse effect of $\mathrm{PE}$ on endometrial receptivity seems to be offset, at least in part, by the availability of good quality embryo for transfer in women with a high ovarian response. In contrast, elevated $\mathrm{P}$ level results in reduced pregnancy in patients with a low ovarian response, who tends to have poorer quality embryos that counterpart with high ovarian response. Table 2 summarizes the studies discussed above.

\section{Which P Thresholds Are Best to Identify Patients at Risk of Implantation Failure due to PE in a Fresh Embryo Transfer?}

Some studies have examined the impact of different $\mathrm{P}$ thresholds on fresh embryo transfer IVF/ICSI pregnancy outcomes. In one study, $\mathrm{Xu}$ et al. assessed the effect of PE on the day of hCG on pregnancy following fresh and frozen embryo transfer (FET) as a function of the ovarian response to COS: high ( $\geq 20$ oocytes; $n=2,023)$, poor ( $\leq 4$ oocytes; $n=27)$, or intermediate $(n=8,205)$ (14). The P cutoff points associated with decreased pregnancy outcomes in fresh embryo transfer cycles were $1.5 \mathrm{ng} / \mathrm{ml}$ for poor responders, $1.75 \mathrm{ng} / \mathrm{ml}$ for intermediate responders, and $2.75 \mathrm{ng} / \mathrm{ml}$ for high responders. The authors also observed that $\mathrm{P}$ mean values differed according to ovarian response $(1.89 \pm 0.66 \mathrm{ng} / \mathrm{ml}$ in high responders, $1.47 \pm 0.47 \mathrm{ng} / \mathrm{ml}$ in intermediate responders, and $1.18 \pm 0.48 \mathrm{ng} / \mathrm{ml}$ in poor responders, $p<0.001$ ), with PE being more common in the high ovarian response group than intermediate and poor ovarian response groups.

Furthermore, whereas OPRs were negatively affected by PE in fresh embryo transfer IVF/ICSI cycles, no detrimental effect was reported in the FET cycles. A multivariate logistic regression analysis showed that the rise in P level was associated with the number of oocytes retrieved, FSH dose, and estradiol values on the day of HCG administration. Last, the authors found that the detrimental effect of PE on the implantation rate and OPR were independent of oocyte quality (14).

In another study, Venetis et al. retrospectively analyzed 3,296 fresh IVF/ICSI cycles to assess the effect of PE on live birth rates (LBR) (13). A bivariate analysis reported no statistical difference in the LBRs when patients with normal $P$ values $(<1.5 \mathrm{ng} / \mathrm{ml})$ were compared to patients with PE ( $\geq 1.5 \mathrm{ng} / \mathrm{ml}$; OR: $0.78,95 \%$ confidence interval (CI): 0.56-1.09). However, a multivariable regression analysis showed an overall decrease in LBR in the elevated P level group (OR: 0.68, 95\% CI: 0.48-0.97). The study also assessed whether the effect of PE on LBR was associated with the ovarian response. There was no statistically significant impact of PE on LBRs in both low ( $<6$ oocytes, $n=796$ cycles) and high ( $>18$ oocytes, $n=730$ cycles) ovarian response groups, whereas negative effect of $\mathrm{PE}$ was reported in normal responders (6-18 oocytes, $n=1,770$ cycles) with threshold levels as low as $0.9 \mathrm{ng} / \mathrm{ml}$ being significant. The authors reported that the number of oocytes and female age were the most common confounding factors for PE (13).

In a recent cohort study performed by Shufaro et al., the impact of late follicular phase PE was also assessed as a function of ovarian response to COS. The authors included 8,649 IVF/ICSI cycles performed in women aged $33.9 \pm 5.8$ years in 
TABLE 2 | Characteristics of included studies to discuss if progesterone elevation (PE) on the day of hCG was associated with negative fresh embryo transfer IVF-ICSI outcomes in all patient subgroups.

\begin{tabular}{|c|c|c|c|c|}
\hline $\begin{array}{l}\text { Reference and place } \\
\text { of study conducted }\end{array}$ & Design & Patient population & Intervention/method & Results \\
\hline
\end{tabular}

\begin{tabular}{lll}
\hline Venetis et al. (13) & Retrospective & A total of 3,296 women \\
country: Greece & analysis & undergoing fresh IVF/ICSI
\end{tabular}

Simple bivariate analyses and $\quad$ PE negatively impacted pregnancy success

multivariate analyses was done to with levels as low as $0.8-1.1 \mathrm{ng} / \mathrm{ml}$ (OR: 0.79, compare PE and LBR according to $\quad 95 \% \mathrm{Cl}$ : 0.67-0.95). The magnitude of effect serum P levels $\leq 1.5$ versus $>1.5 \mathrm{ng} / \mathrm{ml}$ size increased as P level reached $1.2 \mathrm{ng} / \mathrm{ml}$ (OR: on the day of HCG administration and $\quad 0.67,95 \% \mathrm{Cl}: 0.53-0.84)$, and became stable compared among low (<6 oocytes), thereafter normal (6-18 oocytes), and high (>18 oocytes) responders

\begin{tabular}{|c|c|c|c|c|}
\hline $\begin{array}{l}\text { Andersen et al. (26) } \\
\text { country: Europe } \\
\text { ( } 22 \text { centers): } 10 \text { in } \\
\text { Denmark, } 2 \text { in Finland, } \\
4 \text { in Norway, and } 6 \text { in } \\
\text { Sweden }\end{array}$ & $\begin{array}{l}\text { Retrospective } \\
\text { analysis }\end{array}$ & $\begin{array}{l}\text { A total of } 475 \text { patients } \\
\text { undergoing IVF/ICSI following } \\
\text { ovarian stimulation with } \\
\text { GnRH agonist and rFSH with } \\
\text { or without rLH administration } \\
\text { from day } 6 \text { of stimulation } \\
\text { were included }\end{array}$ & $\begin{array}{l}\text { The study was aimed to explore the } \\
\text { association between the number } \\
\text { of eggs and live birth outcomes, a } \\
\text { likelihood logistic model was used to } \\
\text { compare progesterone concentrations } \\
\text { in two groups }\end{array}$ & $\begin{array}{l}\text { Progesterone concentration was strongly } \\
\text { associated with the number of follicles and } \\
\text { retrieved oocytes. There was no significant } \\
\text { association between the late-follicular phase } \\
\text { progesterone concentration and clinical } \\
\text { pregnancy rate }\end{array}$ \\
\hline $\begin{array}{l}\text { Griesinger et al. (11) } \\
\text { country: meta analysis } \\
\text { data collected from } \\
\text { different study IVF } \\
\text { centers in USA and } \\
\text { Europe }\end{array}$ & $\begin{array}{l}\text { Retrospective } \\
\text { combined analysis }\end{array}$ & $\begin{array}{l}\text { 1,866 women undergoing } \\
\text { IVF/ICSI with available serum } \\
\text { P levels on the day of hCG }\end{array}$ & $\begin{array}{l}\text { Univariate and multivariate analyses } \\
\text { was done to assess association } \\
\text { between elevated } \mathrm{P} \text { level on the } \\
\text { day of hCG, according to serum P } \\
\text { levels } \leq 1.5 \text { versus }>1.5 \mathrm{ng} / \mathrm{ml} \text { and } \\
\text { compared among low ( } 1-5 \text { oocytes } \\
\text { retrieved), normal ( } 6-18 \text { oocytes), and } \\
\text { high (>18 oocytes) responders }\end{array}$ & $\begin{array}{l}\text { The incidence of PE was } 4.5 \text { and } 19.0 \% \text { in low } \\
\text { responders and high responders, respectively. } \\
\text { Overall, OPRs per started cycle were significantly } \\
\text { lower in women with PE (OR: 0.55; } 95 \% \mathrm{Cl} \text { : } \\
0.37-0.81) \text {. However, a subgroup analysis } \\
\text { showed that P level }>1.5 \mathrm{ng} / \mathrm{ml} \text { was associated } \\
\text { with decreased pregnancy rates in low to normal } \\
\text { responders, but not in high responders }\end{array}$ \\
\hline $\begin{array}{l}\text { Requena et al. (33) } \\
\text { country: Spain }\end{array}$ & $\begin{array}{l}\text { Retrospective } \\
\text { cohort study }\end{array}$ & $\begin{array}{l}\text { A total of } 2,850 \text { women } \\
\text { were classified on basis of } \\
\text { basis of } P \text { level into following } \\
\text { groups: }<0.5 \mathrm{ng} / \mathrm{ml}(<\mathrm{p} 10) \\
0.50-0.70 \mathrm{ng} / \mathrm{ml},(p 10-p 25) \\
0.71-1.00 \mathrm{ng} / \mathrm{ml}(\mathrm{p} 25-p 50) \\
1.01-1.40 \mathrm{ng} / \mathrm{ml}(\mathrm{p} 50-p 75) \\
1.41-1.80 \mathrm{ng} / \mathrm{ml}(\mathrm{p} 75-p 90) \\
\text { and }>1.81 \mathrm{ng} / \mathrm{ml}(>p 90)\end{array}$ & $\begin{array}{l}\text { CPR and implantation rate was } \\
\text { assessed on the basis of five distinct } \\
\text { serum } \mathrm{P} \text { levels }\end{array}$ & $\begin{array}{l}\text { P levels neither had a negative impact on the } \\
\text { oocyte quality and endometrial receptivity nor did } \\
\text { it affect pregnancy success. Only in the group } \\
\text { of } P \text { level }>1.80 \mathrm{ng} / \mathrm{ml} \text { there was a marginally } \\
\text { significant negative impact on pregnancy rates } \\
\text { (OR: } 0.73,95 \% \mathrm{Cl}: 0.61-0.99 \text { ) }\end{array}$ \\
\hline $\begin{array}{l}\text { Cruz et al. (33) } \\
\text { country: Spain }\end{array}$ & $\begin{array}{l}\text { Retrospective } \\
\text { study }\end{array}$ & $\begin{array}{l}\text { A retrospective analysis of } \\
1,800 \text { cycles comparing } \\
\text { high }(>1.5 \mathrm{ng} / \mathrm{ml}) \text { or low } \\
\text { (<1.5 } \mathrm{ng} / \mathrm{ml}) \text { progesterone } \\
\text { levels in patients undergoing } \\
\text { controlled stimulation } \\
\text { classified as high responders } \\
\text { (E2 }>3,000 \mathrm{pg} / \mathrm{ml}) \text { was done }\end{array}$ & $\begin{array}{l}\text { The study aimed to determine the } \\
\text { influence of high progesterone levels } \\
\text { on clinical outcomes in high ovarian } \\
\text { response }\end{array}$ & $\begin{array}{l}\text { There was no significant differences in the } \\
\text { analyzed parameters, namely, number of } \\
\text { retrieved oocytes ( } 17.2 \pm 0.8 \text { versus } 17.3 \pm 0.4) \text {, } \\
\text { number of transferred embryos ( } 1.81 \pm 0.08 \\
\text { versus } 1.85 \pm 0.02) \text {, pregnancy rate }(59.9 \text { versus } \\
54.6 \% \text { ), implantation rate ( } 41.2 \text { versus } 39.7 \% \text { ), } \\
\text { and miscarriage rate ( } 22.6 \text { versus } 28.6 \% \text { ) for high } \\
\text { and low progesterone levels, respectively in case } \\
\text { of high ovarian response }\end{array}$ \\
\hline
\end{tabular}

IVF, in vitro fertilization; LBR, live birth rates; RCT, randomized controlled trials; $h M G$, human menopausal gonadotropin; rhFSH, recombinant human follicle stimulating hormone; CPR, clinical pregnancy rates; FET, frozen-embryo transfer; GnRha, gonadotropin releasing hormone agonist; P, progesterone; OPR, ongoing pregnancy rate; ET, embryo transfer; hCG, human chorionic gonadotropin.

whom pituitary suppression was used (GnRH agonist: $49.8 \%$ of cycles; GnRH antagonist: $50.2 \%$ of cycles). The mean number of follicles $>14 \mathrm{~mm}$ in diameter recorded before hCG administration was $8.07 \pm 3.31$ (range: $3-15$ follicles). In addition to measure late follicular phase P levels, the authors determined the progesterone-to-follicle index (PFI), which was considered to be more representative of the intrinsic follicular properties that are related to cycle outcome than the total blood P. The PFI was calculated by dividing the blood $\mathrm{P}$ by the number of follicles $\geq 14 \mathrm{~mm}$. The CPR was calculated against the range of PFI values and serum $P$ levels. Overall, the mean late follicular phase $P$ level was $2.22 \pm 1.33 \mathrm{nmol} / \mathrm{l}$, and the mean PFI was $0.32 \pm 0.25 \mathrm{nmol} / \mathrm{l}$ follicle on the day of hCG. The (reverse) ORs for pregnancy after a fresh embryo transfer were 1.11 [95\% confidence interval (CI): 1.07-1.16] for serum P and 4.10 (95\% CI: 3.18-5.28) for the PFI. These authors reported that elevated $\mathrm{P}$ levels were associated with a lower pregnancy rate only when they reached the $>93 \mathrm{rd}$ percentile. In contrast, the PFI was inversely and linearly related to the pregnancy rate for the whole range of values. The authors concluded that a late increase in $\mathrm{P}$ level was detrimental if it resulted from increased $\mathrm{P}$ production per follicle (high PFI), but not if it caused by additional follicular recruitment (45).

Last, recent reports have examined the issue from a different perspective. In one study, Lee et al. assessed the effect 
of the duration of preovulatory PE on pregnancy rates (15). Persistence of $\mathrm{PE}$ for 2 days or more was significantly associated with a reduction in the CPR (39.4 versus $20.7 \%$; $p<0.001$ ). The overall incidence of PE was $28.4 \%(n=173$ of 610$)$. Among them, $83.2 \%(n=144)$ had 1 day of PE, $12.7 \%(n=22)$ had 2 days, and $4.1 \%(n=7)$ had 3 days of PE. The serum P concentration on the LH surge day in those women without PE was $3.2 \pm 1.0 \mathrm{nmol} / \mathrm{l}(0.9-4.9)$ [mean $\pm \mathrm{SD}$ (range)], whereas in those with PE it was $6.4 \pm 1.7 \mathrm{nmol} / \mathrm{l}(5.0-15.3)$; the serum E2 concentration was $1,082 \pm 329 \mathrm{pmol} / \mathrm{l}(376-2,222)$ and $1,045 \pm 428 \mathrm{pmol} / \mathrm{l}(440-2,649)$, respectively. There were no significant differences in both clinical and ongoing PR (39.0 versus $37.3 \%$ and 32.5 versus $31.7 \%$ ) between those with and without PE on the day of LH surge. The incidence of PE in frozen-thawed embryo transfers in subsequent natural cycles (FET-NC) was not significantly different than that in stimulated cycles (15). In another study, Lai et al. evaluated the relationship between serum levels of $\mathrm{P}$ and estradiol (P:E ratio) measured on the day of hCG administration on ART clinical outcomes of 139 infertile women with normal ovarian reserve treated with a long GnRH-a protocol. The authors showed that P:E ratio was significantly higher among patients with premature luteinization ( $\mathrm{PL}, n=41$ ), defined by a $\mathrm{P}: \mathrm{E} \geq 1.2$ using receiver operator characteristic analysis, than in non-PL $(n=98)$ group $(2.4 \pm 1.5$ and $0.6 \pm 0.3$, respectively), but P:E ratio did not correlate with pregnancy outcomes after a fresh embryo transfer (46).

A critical aspect to discuss about $\mathrm{P}$ thresholds concerns the shortcomings of the currently rapid immunoassays for steroid determination. These assays have been associated with poorly agreeable results due to low assay specificity, poor optimization of methods over the large concentration ranges observed clinically, and inadequate standardization $(47,48)$. Although direct immunoassay platforms are fully automated, easy-to-use, inexpensive, and allow rapid detection with a high throughput, there is limited data regarding the performance and precision of these immunoassay systems, particularly in the lower range of detectable $\mathrm{P}$ concentrations $(<2.5 \mathrm{ng} / \mathrm{ml})$ (48). For automated immunoassay platforms, intra-assay variability is generally expressed as an averaged variability across discrete analyte standards spanning low, middle, and high ranges of P levels. It has been argued that these systems should not be used clinically for low detection limits such as measuring $\mathrm{P}$ with values corresponding to $\sim 1 \mathrm{ng} / \mathrm{ml}$. Due to the non-uniform sensitivity of $\mathrm{P}$ measurement assays, especially in the low range of $\mathrm{P}$, thus, caution should be applied to adopt any $\mathrm{P}$ threshold level for managing purposes, such as the recommendation of freezing all embryos in cycles with $\mathrm{P}$ elevation on day of hCG administration based on a single measurement and using specific low range $P$ cutoff points (49).

Collectively, these observations indicate that there is still no clarity on the cutoff value of $\mathrm{P}$ above which it negatively affects pregnancy success in fresh embryo transfer IVF/ICSI cycles. Alternative approaches including the determination of PE duration and measurement of $\mathrm{P}$ to follicle index ratio (PF) may prove useful to assess the role of follicular phase PE on pregnancy success, but further research is needed to confirm their clinical utility.

\section{Should a "Freeze-All" Policy be Adopted in All the Cycles With PE on the Day of hCG?}

Based on the existing literature, it is clear that the association between PE and IVF/ICSI success does not follow a binomial distribution, i.e., PE not always halt implantation regardless of the threshold level adopted. Therefore, the next critical question for clinicians would be to know the absolute pregnancy reduction rate in the face of PE.

According to the largest systematic review and meta-analysis published to date, the OR for pregnancy reduction associated with PE was 0.64 (95\% CI: 0.54-0.76). Transformation of the OR mentioned above into absolute pregnancy rate reduction (APRR) translated in 10.1\% APRR (95\% CI: 6-14\%) (12). Using these assumptions, it is possible to estimate the net effect of performing fresh embryo transfer in cases of PE for a given IVF Program. In Table 3, we estimated the net effect of PE on pregnancy for an IVF center performing 1,000 cycles per year with an overall baseline pregnancy rate of $40 \%$ per fresh embryo transfer, considering three different scenarios of PE incidence as commonly reported in the literature. According to these estimations, the net effect on pregnancy reduction for the overall population subjected to fresh embryo transfer IVF/ICSI cycles in a given IVF center would range from 0.5 to $3.0 \%$ in the best and worst case scenarios, respectively. It means clinicians in that hypothetical center would need to monitor P levels in 1,000 cycles and intervene in 50-300 cycles with PE to potentially avoid 2-12 implantation failures by applying the freeze-all strategy. Notably, despite improvements in cryopreservation techniques and an overall favorable outcome with the transfer of frozen-thawed vitrified embryos $(42,50,51)$, pregnancy rates reported by individual centers still vary, with an success rate of approximately $50 \%$ (52). As a result, the final net effect of $\mathrm{PE}$ on pregnancy rates may be offset even further.

Thus, fresh embryo transfers in IVF/ICSI cycles with PE should not be disregarded, particularly when supranumerary embryos will make cryopreservation inevitable. Furthermore, recent evidence indicates that individualization of the luteal phase support by addition of LH activity to progesterone supplementation for fresh ET can overcome the luteal phase deficiency in infertile patients submitted to IVF/ICSI cycles with GnRH antagonist cotreatment who underwent fresh embryo transfer. There are still concerns that the adoption of a universal segmentation policy

TABLE 3 | Different scenarios to evaluate net effect of PE on pregnancy for an IVF center performing 1,000 cycles per year.

\begin{tabular}{lccc}
\hline Cycles & Scenario 1 & Scenario 2 & Scenario 3 \\
\hline Cycles with PE $(\%)$ & 5 & 15 & 30 \\
Cycles with PE $(N)$ & 50 & 150 & 300 \\
Expected pregnancies in & 20 & 60 & 120 \\
the subgroup of PEb $(N)$ & 18 & 54 & 108 \\
Achieved pregnancies & & & $12(3.0 \%)^{d}$ \\
corrected by APRR $(N)$ & $2(0.5 \%)^{d}$ & $6(1.5 \%)^{d}$ & \\
Overall pregnancy reduction & & &
\end{tabular}

aper 1,000 cycles.

${ }^{b}$ Considering $40 \%$ as the overall PR per fresh embryo transfer.

${ }^{\circ}$ Considering $10 \%$ absolute pregnancy rate reduction (APRR).

${ }^{d} 400$ pregnancies would be expected overall per 1,000 cycles. 
for PE might compromise the overall health of the mother and generated offspring (53). There have been reports of increased incidence of placenta accreta, preeclampsia, macrosomia, and large for gestational age as a result of the transfer of frozen-thawed embryos compared to fresh counterparts (54). Along the same lines, adoption of a freeze-all policy would require additional embryo manipulation that might induce epigenetic changes, and thus further add risk to children born from frozen-thawed embryo transfer cycles (55-61).

In conclusion, the current limitations of progesterone assays, the conflicting data on $\mathrm{P}$ thresholds, and the equivocal clinical implications of PE to pregnancy outcomes should prompt clinicians to critically evaluate their dataset and practices to determine the usefulness of routine measurement of progesterone levels on the day of hCG trigger and adopting a freeze-all strategy to all cycles of PE. At present, the indiscriminate adoption of $1.5 \mathrm{ng} / \mathrm{ml}$ cut off to adopt an embryo freeze-all strategy is not evidencebased. Moreover, the net effect of PE on pregnancy success of ART units is likely minimal.

\section{FUTURE ASPECTS}

An analysis of the freeze all policy adopted in all the cycles with $\mathrm{PE}$ on the day of hCG, taking into account cost-effectiveness, patient-centeredness, and time to live-birth has to be carried out to better assess the clinical validity of such additional interventions. Furthermore, development of robust assays to measure $\mathrm{P}$ at low limit levels is essential to determine PE cutoff levels with clinical impact. Better identification of the patient profile at higher risk of implantation failure due to PE on the late follicular phase and the optimal algorithm for PE determination is of utmost importance for clinicians providing care to infertile couples undergoing ART.

\section{CONCLUSION}

Conflicting evidence still prevails concerning the effect of P elevation on the day of hCG trigger in fresh embryo transfer IVF/ICSI pregnancy outcomes. Clinicians should exercise caution to adopt cutoff values of $\mathrm{P}$ in the clinical management of patients with $\mathrm{PE}$ due to limitations of exiting assays to measure progesterone at the lower levels and the lack of unequivocal evidence indicating a negative effect of PE on pregnancy success in fresh embryo transfer IVF/ICSI cycles. Gonadotropin type and regimen, as routinely used during COS, seems to have an eligible effect on late follicular phase progesterone levels. However, given the higher potency of recombinant gonadotropin preparations than urinary

\section{REFERENCES}

1. Spencer TE, Johnson GA, Burghardt RC, Bazer FW. Progesterone and placental hormone actions on the uterus: insights from domestic animals. Biol Reprod (2004) 71(1):2-10. doi:10.1095/biolreprod.103.024133

2. Gougeon A. Dynamics of human follicular growth: morphologic, dynamic, and functional aspects. Ovary (2004) 2:25-43. doi:10.1016/B978-0124445628/50003-3

3. Hoff JD, Quigley ME, Yen SS. Hormonal dynamics at midcycle: a reevaluation. J Clin Endocrinol Metab (1983) 57(4):792-6. doi:10.1210/jcem57-4-792 counterparts and the possibility of small dose adjustments using the former, individualized dose adaptation can be used during COS to modulate the GCs progesterone output. A potential adverse impact of PE on pregnancy success does not seem to affect the overall patient population equally, with high responders to COS being less susceptible to the possible detrimental effect of PE. An individualized approach should be used in cases of PE, which could include fresh embryo transfers in hyper-responders with low risk of OHSS and in patients with supranumerary embryos undergoing blastocyst transfer. In normal responders with PE undergoing day 3 fresh embryo transfers, a "freeze-all" strategy might be considered. As for poor responders, the optimal strategy in the face of PE is yet to be determined.

\section{AUTHORS CONTRIBUTIONS}

GK, SG, DR, SD, KI, MP, JS, KM, and KM were involved in critical analysis of data and provided expert comments and amendments for formulation of the manuscript. PT participated in its design and coordination, primarily searched the literature, and helped to draft the manuscript. PD organized the meetings and helped to formulate the study questions, participated in its design and coordination, primarily searched the literature, and helped to draft the manuscript. SE designed the review, helped in coordination and literature search, provided critical analysis of data, and drafted the manuscript. All authors approved its final version.

\section{ACKNOWLEDGMENTS}

Dr. Shivali Arora of Knowledge Isotopes Pvt. Ltd. (http://www. knowledgeisotopes.com/) for the medical writing support funded by Merck India, an affiliate of Merck KGaA, Darmstadt, Germany.

\section{FUNDING}

The panel of ART experts was organized by Merck, India, represented by PD. The data were assembled, analyzed, and interpreted by a panel of Indian experts in ART. These activities were organized and funded by Merck, India, an affiliate of Merck KGaA, Darmstadt, Germany.

\section{SUPPLEMENTARY MATERIAL}

The Supplementary Material for this article can be found online at https://www.frontiersin.org/articles/10.3389/fendo.2018.00201/ full\#supplementary-material.

4. Payne AH, Hales DB. Overview of steroidogenic enzymes in the pathway from cholesterol to active steroid hormones. Endocr Rev (2004) 25(6):947-70. doi:10.1210/er.2003-0030

5. Seger R, Hanoch T, Rosenberg R, Dantes A, Merz WE, Strauss JF III, et al. The ERK signaling cascade inhibits gonadotropin-stimulated steroidogenesis. J Biol Chem (2001) 276(17):13957-64. doi:10.1074/jbc.M006852200

6. Leao Rde B, Esteves SC. Gonadotropin therapy in assisted reproduction: an evolutionary perspective from biologics to biotech. Clinics (Sao Paulo) (2014) 69(4):279-93. doi:10.6061/clinics/2014(04)10

7. Czyzyk A, Podfigurna A, Genazzani AR, Meczekalski B. The role of progesterone therapy in early pregnancy: from physiological role to therapeutic 
utility. Gynecol Endocrinol (2017) 33:421-4. doi:10.1080/09513590.2017. 1291615

8. Lessey BA. Two pathways of progesterone action in the human endometrium: implications for implantation and contraception. Steroids (2003) 68(10): 809-15. doi:10.1016/j.steroids.2003.09.004

9. Blakemore JK, Kofinas JD, McCulloh DH, Grifo J. Serum progesterone trend after day of transfer predicts live birth in fresh IVF cycles. J Assist Reprod Genet (2017) 34(3):339-43. doi:10.1007/s10815-016-0859-1

10. Bosch E, Labarta E, Crespo J, Simon C, Remohi J, Jenkins J, et al. Circulating progesterone levels and ongoing pregnancy rates in controlled ovarian stimulation cycles for in vitro fertilization: analysis of over 4000 cycles. Hum Reprod (2010) 25(8):2092-100. doi:10.1093/humrep/deq125

11. Griesinger G, Mannaerts B, Andersen CY, Witjes H, Kolibianakis EM, Gordon K, et al. Progesterone elevation does not compromise pregnancy rates in high responders: a pooled analysis of in vitro fertilization patients treated with recombinant follicle-stimulating hormone/gonadotropin-releasing hormone antagonist in six trials. Fertil Steril (2013) 100(6):1622-8.e1-3. doi:10.1016/ j.fertnstert.2013.08.045

12. Venetis C, Kolibianakis E, Bosdou J, Tarlatzis B. Progesterone elevation and probability of pregnancy after IVF: a systematic review and meta-analysis of over 60000 cycles. Hum Reprod Update (2013) 19(5):433-57. doi:10.1093/ humupd/dmt014

13. Venetis CA, Kolibianakis EM, Bosdou JK, Lainas GT, Sfontouris IA, Tarlatzis BC, et al. Estimating the net effect of progesterone elevation on the day of hCG on live birth rates after IVF: a cohort analysis of 3296 IVF cycles. Hum Reprod (2015) 30(3):684-91. doi:10.1093/humrep/deu362

14. Xu B, Li Z, Zhang H, Jin L, Li Y, Ai J, et al. Serum progesterone level effects on the outcome of in vitro fertilization in patients with different ovarian response: an analysis of more than 10,000 cycles. Fertil Steril (2012) 97(6):1321-7.e1-4. doi:10.1016/j.fertnstert.2012.03.014

15. Lee VCY, Li RHW, Chai J, Yeung TWY, Yeung WSB, Ho PC, et al. Effect of preovulatory progesterone elevation and duration of progesterone elevation on the pregnancy rate of frozen-thawed embryo transfer in natural cycles. Fertil Steril (2014) 101(5):1288-93. doi:10.1016/j.fertnstert.2014. 01.040

16. Lee VCY, Li RHW, Ng EHY, Yeung WSB, Ho PC. Luteal phase support does not improve the clinical pregnancy rate of natural cycle frozen-thawed embryo transfer: a retrospective analysis. Eur J Obstet Gynecol Reprod Biol (2013) 169(1):50-3. doi:10.1016/j.ejogrb.2013.02.005

17. Younis JS, Simon A, Laufer N. Endometrial preparation: lessons from oocyte donation. Fertil Steril (1996) 66(6):873-84. doi:10.1016/S0015-0282 (16)58677-4

18. Fanchin R, Righini C, Olivennes F, Ferreira AL, de Ziegler D, Frydman R. Consequences of premature progesterone elevation on the outcome of in vitro fertilization: insights into a controversy. Fertil Steril (1997) 68(5):799-805. doi:10.1016/S0015-0282(97)90655-5

19. Schoolcraft W, Sinton E, Schlenker T, Huynh D, Hamilton F, Meldrum DR. Lower pregnancy rate with premature luteinization during pituitary suppression with leuprolide acetate. Fertil Steril (1991) 55(3):563-6. doi:10.1016/ S0015-0282(16)54186-7

20. Gurbuz AS, Deveer R, Kucuk M, Ozcimen N, Incesu D, Koseoglu S. Is it possible to prevent ovarian hyperstimulation syndrome by gonadotropinreleasing hormone agonist triggering and modified luteal support in patients with polycystic ovarian morphology? J Clin Med Res (2016) 8(5):396-401. doi:10.14740/jocmr2500w

21. Cui N, Zhang J, Xu Y, Jiang L, Yang A, Hao G. Premature progesterone rise positively correlates with clinical pregnancy rate in in vitro fertilization (IVF) and intracytoplasmic sperm injection (ICSI) patients with good ovarian response. Horm Metab Res (2017) 49(5):372-9. doi:10.1055/s-0043-104384

22. Kumar P, Sharma A. Gonadotropin-releasing hormone analogs: understanding advantages and limitations. J Hum Reprod Sci (2014) 7(3):170. doi:10.4103/0974-1208.142476

23. Roque M, Valle M, Guimarães F, Sampaio M, Geber S. Freeze-all policy: fresh vs. frozen-thawed embryo transfer. Fertil Steril (2015) 103(5):1190-3. doi:10.1016/j.fertnstert.2015.01.045

24. Labarta E, Martínez-Conejero J, Alamá P, Horcajadas J, Pellicer A, Simón C, et al. Endometrial receptivity is affected in women with high circulating progesterone levels at the end of the follicular phase: a functional genomics analysis. Hum Reprod (2011) 26(7):der126. doi:10.1093/humrep/der126
25. Andersen AN, Devroey P, Arce J-C. Clinical outcome following stimulation with highly purified hMG or recombinant FSH in patients undergoing IVF: a randomized assessor-blind controlled trial. Hum Reprod (2006) 21(12): 3217-27. doi:10.1093/humrep/del284

26. Andersen CY, Bungum L, Andersen AN, Humaidan P. Preovulatory progesterone concentration associates significantly to follicle number and $\mathrm{LH}$ concentration but not to pregnancy rate. Reprod Biomed Online (2011) 23(2): 187-95. doi:10.1016/j.rbmo.2011.04.003

27. Kolibianakis EM, Venetis CA, Bontis J, Tarlatzis BC. Significantly lower pregnancy rates in the presence of progesterone elevation in patients treated with GnRH antagonists and gonadotrophins: a systematic review and meta-analysis. Curr Pharm Biotechnol (2012) 13(3):464-70. doi:10.2174/ 138920112799361927

28. Bosch E, Valencia I, Escudero E, Crespo J, Simón C, Remohí J, et al. Premature luteinization during gonadotropin-releasing hormone antagonist cycles and its relationship with in vitro fertilization outcome. Fertil Steril (2003) 80(6):1444-9. doi:10.1016/j.fertnstert.2003.07.002

29. Papanikolaou EG, Kolibianakis EM, Pozzobon C, Tank P, Tournaye H, Bourgain C, et al. Progesterone rise on the day of human chorionic gonadotropin administration impairs pregnancy outcome in day 3 single-embryo transfer, while has no effect on day 5 single blastocyst transfer. Fertil Steril (2009) 91(3):949-52. doi:10.1016/j.fertnstert.2006.12.064

30. Seow K-M, Lin Y-H, Huang L-W, Hsieh B-C, Huang S-C, Chen CY, et al. Subtle progesterone rise in the single-dose gonadotropin-releasing hormone antagonist (cetrorelix) stimulation protocol in patients undergoing in vitro fertilization or intracytoplasmic sperm injection cycles. Gynaecol Endocrinol (2007) 23(6):338-42. doi:10.1080/09513590701403629

31. Ubaldi F, Albano C, Peukert M, Riethmüller-Winzen H, Camus M, Smitz J, et al. Endocrinology: subtle progesterone rise after the administration of the gonadotrophin-releasing hormone antagonist cetrorelix in intracytoplasmic sperm injection cycles. Hum Reprod (1996) 11(7):1405-7. doi:10.1093/ oxfordjournals.humrep.a019409

32. Eleno I, Matallin Evangelio P, Gavila N, Alfayate R, Mauri M, Cremades N, et al. Predictive value of plasma progesterone on hCG administration day in the outcome of IVF-ET cycles [Valor predictivo de la concentración plasmática de progesterona el dia de la administración de la hCG en los resultados de ciclos de FIV/ICSI]. Revista Iberoamericana de Fertilidad (2006) 23(4):257-64.

33. Requena A, Cruz M, Bosch E, Meseguer M, Garcia-Velasco JA. High progesterone levels in women with high ovarian response do not affect clinical outcomes: a retrospective cohort study. Reprod Biol Endocrinol (2014) 12:69. doi:10.1186/1477-7827-12-69

34. Devroey P, Pellicer A, Andersen AN, Arce J-C; Group MiGACwSETT. A randomized assessor-blind trial comparing highly purified hMG and recombinant FSH in a GnRH antagonist cycle with compulsory singleblastocyst transfer. Fertil Steril (2012) 97(3):561-71. doi:10.1016/j.fertnstert. 2011.12.016

35. Lawrenz B, Beligotti F, Engelmann N, Gates D, Fatemi H. Impact of gonadotropin type on progesterone elevation during ovarian stimulation in $\mathrm{GnRH}$ antagonist cycles. Hum Reprod (2016) 31(11):2554-60. doi:10.1093/humrep/ dew213

36. Andersen CY, Ezcurra D. Human steroidogenesis: implications for controlled ovarian stimulation with exogenous gonadotropins. Reprod Biol Endocrinol (2014) 12:128. doi:10.1186/1477-7827-12-128

37. Smyth C, Miro F, Whitelaw P, Howles C, Hillier S. Ovarian thecal/interstitial androgen synthesis is enhanced by a follicle-stimulating hormone-stimulated paracrine mechanism. Endocrinology (1993) 133(4):1532-8. doi:10.1210/ endo.133.4.8404591

38. Thuesen L, Loft A, Egeberg A, Smitz J, Petersen JH, Andersen AN. A randomized controlled dose-response pilot study of addition of hCG to recombinant FSH during controlled ovarian stimulation for in vitro fertilization. Hum Reprod (2012) 27(10):3074-84. doi:10.1093/humrep/des256

39. Ezcurra D, Humaidan P. A review of luteinising hormone and human chorionic gonadotropin when used in assisted reproductive technology. Reprod Biol Endocrinol (2014) 12:95. doi:10.1186/1477-7827-12-95

40. Devroey P, Boostanfar R, Koper N, Mannaerts B, Ijzerman-Boon P, Fauser BC, et al. A double-blind, non-inferiority RCT comparing corifollitropin alfa and recombinant FSH during the first seven days of ovarian stimulation using a GnRH antagonist protocol. Hum Reprod (2009) 24(12):3063-72. doi:10.1093/ humrep/dep291 
41. Miller KF, Behnke EJ, Arciaga RL, Goldberg JM, Chin NW, Awadalla SG. The significance of elevated progesterone at the time of administration of human chorionic gonadotropin may be related to luteal support. J Assist Reprod Genet (1996) 13(9):698-701. doi:10.1007/BF02066420

42. Shapiro BS, Daneshmand ST, Garner FC, Aguirre M, Hudson C, Thomas S, et al. Evidence of impaired endometrial receptivity after ovarian stimulation for in vitro fertilization: a prospective randomized trial comparing fresh and frozen-thawed embryo transfer in normal responders. Fertil Steril (2011) 96(2):344-8. doi:10.1016/j.fertnstert.2011. 02.059

43. Cruz M, Requena A, Guillen A, Cerrillo M, García-Velasco J. High progesterone levels in high ovarian response do not affect clinical outcomes. Fertil Steril (2013) 100(3):S109. doi:10.1016/j.fertnstert.2013.07.1674

44. Khalaf Y, El-Toukhy T, Coomarasamy A, Kamal A, Bolton V, Braude P. Selective single blastocyst transfer reduces the multiple pregnancy rate and increases pregnancy rates: a pre-and post-intervention study. BJOG (2008) 115(3):385-90. doi:10.1111/j.1471-0528.2007.01584.x

45. Shufaro Y, Sapir O, Oron G, Haroush AB, Garor R, Pinkas H, et al. Progesterone-to-follicle index is better correlated with in vitro fertilization cycle outcome than blood progesterone level. Fertil Steril (2015) 103(3): 669-74.e3. doi:10.1016/j.fertnstert.2014.11.026

46. Lai TH, Lee FK, Lin TK, Horng SG, Chen SC, Chen YH, et al. An increased serum progesterone-to-estradiol ratio on the day of human chorionic gonadotropin administration does not have a negative impact on clinical pregnancy rate in women with normal ovarian reserve treated with a long gonadotropin releasing hormone agonist protocol. Fertil Steril (2009) 92(2):508-14. doi:10.1016/ j.fertnstert.2008.06.036

47. Stanczyk FZ, Cho MM, Endres DB, Morrison JL, Patel S, Paulson RJ, et al. Limitations of direct estradiol and testosterone immunoassay kits. Steroids (2003) 68(14):1173-8. doi:10.1016/j.steroids.2003.08.012

48. Patton PE, Lim JY, Hickok LR, Kettel LM, Larson JM, Pau KY. Precision of progesterone measurements with the use of automated immunoassay analyzers and the impact on clinical decisions for in vitro fertilization. Fertil Steril (2014) 101(6):1629-36. doi:10.1016/j.fertnstert.2014.02.037

49. Taieb J, Benattar C, Birr AS, Lindenbaum A. Limitations of steroid determination by direct immunoassays. Clin Chem (2002) 48(3):583-5.

50. Aflatounian A, Oskoueian H, Ahmadi S. Can fresh embryo transfers be replaced by cryopreserved-thawed embryo transfers in assisted reproductive cycles? A randomized controlled trial. J Assisted Reprod Genet (2009) 27(7):357-63. doi:10.1007/s10815-010-9412-9

51. Kalra SK, Ratcliffe SJ, Milman L, Gracia CR, Coutifaris C, Barnhart KT, et al. Perinatal morbidity after in vitro fertilization is lower with frozen embryo transfer. Fertil Steril (2011) 95(2):548-53. doi:10.1016/j.fertnstert.2010. 05.049

52. Li R, Qiao J, Wang L, Zhen X, Lu Y. Serum progesterone concentration on day of HCG administration and IVF outcome. Reprod Biomed Online (2008) 16(5):627-31. doi:10.1016/S1472-6483(10)60475-0

53. Haahr T, Roque M, Esteves SC, Humaidan P. GnRH agonist trigger and LH activity luteal phase support versus hCG trigger and conventional luteal phase support in fresh embryo transfer IVF/ICSI cycles - a systematic PRISMA review and meta-analysis. Front Endocrinol (2017) 8:116. doi:10.3389/fendo. 2017.00116

54. Pinborg A, Wennerholm U-B, Romundstad L, Loft A, Aittomaki K, Söderström-Anttila V, et al. Why do singletons conceived after assisted reproduction technology have adverse perinatal outcome? Systematic review and meta-analysis. Hum Reprod Update (2012) 19(2):87-104. doi:10.1093/ humupd/dms044

55. Pinborg A, Henningsen A, Loft A, Malchau S, Forman J, Andersen AN, et al. Large baby syndrome in singletons born after frozen embryo transfer (FET): is it due to maternal factors or the cryotechnique? Hum Reprod (2014) 29(3):618-27. doi:10.1093/humrep/det440

56. Wennerholm U-B, Henningsen A-KA, Romundstad LB, Bergh C, Pinborg A, Skjaerven R, et al. Perinatal outcomes of children born after frozen-thawed embryo transfer: a Nordic cohort study from the CoNARTaS group. Hum Reprod (2013) 28(9):2545-53. doi:10.1093/humrep/det272

57. Ishihara O, Araki R, Kuwahara A, Itakura A, Saito H, Adamson GD, et al. Impact of frozen-thawed single-blastocyst transfer on maternal and neonatal outcome: an analysis of 277,042 single-embryo transfer cycles from 2008 to 2010 in Japan. Fertil Steril (2014) 101(1):128-33. doi:10.1016/j. fertnstert.2013.09.025

58. Kaser DJ, Melamed A, Bormann CL, Myers DE, Missmer SA, Walsh BW, et al. Cryopreserved embryo transfer is an independent risk factor for placenta accreta. Fertil Steril (2015) 103(5):1176-84.e2. doi:10.1016/j.fertnstert.2015. 01.021

59. Sazonova A, Källen K, Thurin-Kjellberg A, Wennerholm U-B, Bergh C. Obstetric outcome in singletons after in vitro fertilization with cryopreserved/ thawed embryos. Hum Reprod (2012) 27(5):1343-50. doi:10.1093/humrep/ des036

60. Hart R, Norman RJ. The longer-term health outcomes for children born as a result of IVF treatment: part I - general health outcomes. Hum Reprod Update (2013) 19(3):232-43. doi:10.1093/humupd/dmt002

61. Meister TA, Rexhaj E, Rimoldi SF, Scherrer U, Sartori C. Effects of perinatal, late foetal, and early embryonic insults on the cardiovascular phenotype in experimental animal models and humans. Vasa (2016) 45(6):439-49. doi:10.1024/0301-1526/a000573

Conflict of Interest Statement: Authors PD and PT were both employed by company Merck Ltd., India. The funders had no role in study design, data collection and analysis, decision to publish, or preparation of the manuscript. All authors declare no conflict of interest.

The reviewer AC and handling Editor declared their shared affiliation.

Copyright (C) 2018 Esteves, Khastgir, Shah, Murdia, Gupta, Rao, Dash, Ingale, Patil, Moideen, Thakor and Dewda. This is an open-access article distributed under the terms of the Creative Commons Attribution License (CC BY). The use, distribution or reproduction in other forums is permitted, provided the original author(s) and the copyright owner are credited and that the original publication in this journal is cited, in accordance with accepted academic practice. No use, distribution or reproduction is permitted which does not comply with these terms. 